\title{
Performance Comparison of Swastika and Rectangular Shaped Microstrip Patch Antenna
}

\author{
Suroj Burlakoti*, Prakash Rai \\ Department of Electronics and Communication Engineering, National College of Engineering, Lalitpur, Nepal \\ Corresponding Email: * er.surojburlakoti@gmail.com
}

\begin{abstract}
In this paper, Microstrip patch antennas with rectangular and swastika shape of patch are designed and its performance parameters are compared with each other. Rectangular and Swastika shaped patch are considered in this paper with common rectangular ground plane. The antenna is simulated at $2.4 \mathrm{GHz}$ using HFSS simulation software .This work mainly includes modification of antenna patch to improve the antenna parameters. The parameters of antenna such as Return loss, VSWR Bandwidth and radiation pattern are compared using simulation. The performance of Swastika shaped antenna was found to be better than rectangular shaped microstrip patch antenna with improved Return Loss, VSWR, Bandwidth and Radiation Pattern.
\end{abstract}

\section{INTRODUCTION}

$\mathrm{W}^{\mathrm{s}+1}$ ITH the advancement in wireless communication technology, the need for light weight and miniature size antennas has become a mandatory requirement in today's world. The most popular antenna in this category is micro-strip patch antenna. The micro-strip patch antenna is a type of radio antenna with a low profile that can be mounted on a flat surface. These antennas consist of a flat rectangular sheet or "patch" of metal, mounted over a larger sheet of metal called as ground plane. The assembly is usually contained inside a plastic radome, which protects the antenna structure from damage [1]. Microstrip patch antennas have major disadvantages like low efficiency, poor polarization purity and very narrow frequency bandwidth. Thick substrate with lower dielectric constant had been proposed to increase the bandwidth and antenna efficiency, but at the expense of larger element size which arose questions over the portability of the antennas. On the other hand, thin substrate with higher dielectric constant had been proposed to minimize antenna size, but it decreased antenna bandwidth and efficiency [2].

Microstrip antennas are low profile, comfortable to planar and non-planar surfaces, simple and inexpensive to manufacture using modern printed-circuit technology, mechanically robust when mounted on rigid surfaces, compatible with Microwave Monolithic Integrated circuit (MMIC) designs, and when the particular patch shape and mode are selected, they are very versatile in terms of resonant frequency, polarization pattern, and impedance [3].

A microstrip patch antenna is widely used because it is lightweight, low profile and simple structure antennas with reliability, mobility and good efficiency [4]. They are most suitable for aerospace and mobile applications. It consist conducting patch on a grounded dielectric substrate. The conducting patch can be of any shape but in practice rectangular, circular and triangular are commonly used shapes because these shapes are less complex and effective. The performance of a patch antenna depend not only the shape of antenna but dielectric constant of the substrate, dimensions of the dielectric substrate and ground are also affects the performance of the patch antenna. It may be possible that all shapes gives different performance on different frequencies.

To support the high mobility necessity for a wireless telecommunication device, compact microstrip antenna is one of the most suitable applications. The development of antenna for wireless communication also requires an antenna with more than one operating frequencies. This is due to many reasons, mainly because there are various wireless communication systems and many telecommunication operators using various frequencies. However the general microstrip patch antennas have some disadvantages such as narrow bandwidth etc. Enhancement of the performance to cover the demanding bandwidth is necessary [5].

\section{RELATED WORK}

For reception and transmission of electromagnetic signal, antennas are very essential part. Microstrip patch antenna is one of the most promoted antenna structure due to their various convenient use and low profile. These antennas are more acceptable for their special feature that they can be directly printed in circuit board. They have various application in wireless communication such as mobile communication, radar application, broadcast television, RFID and in satellite communication etc. [6].

The growth of portable wireless communication devices has pushed designers to design miniature size antennas. The most prized among miniature antenna choices is the microstrip patch antenna. They have significant advantages such as low profile, light weight, relatively low manufacturing cost, and polarization diversity. S. Sharma, B. Bhushan, S. Gupta, and P. Kaur [1] compares the performance of microstrip patch antenna having different shapes of the patch (Square, Elliptical, Annular ring, Triangular) at a frequency of $2.43 \mathrm{GHz}$. To compare and analyze the performance, High Frequency Structure Simulator (HFSS) software was used. The results show that the size of the antenna will be smallest for square shape patch antenna followed by elliptical, triangular and annular ring.

Fifteen different shaped (E, F, inverted F, G, H, I, L, inverted $\mathrm{L}, \mathrm{S}, \mathrm{T}$, inverted $\mathrm{T}$, $\mathrm{U}$, inverted $\mathrm{U}, \mathrm{W}$ and inverted W) conventional microstrip patch antennas along with a dumbbell $(\mathrm{H})$ shaped Defected Ground Structure (DGS) in each are designed and simulated at $2.4 \mathrm{GHz}$ operating frequency using CST Microwave Studio Suite by M. S. Hossain, M. M. Rana, M. S. Anower, and M. K. Islam [2]. The efficiency of microstrip patch antennas are compared in 
terms of surface wave concept and the antenna with $\mathrm{H}$ shaped patch exhibiting total efficiency of $-2.546 \mathrm{~dB}$ is found most efficient. The implementation of this work is highly anticipated to be employed for designing hybrid shaped patches for WLAN, wireless network (Wi-Fi and Bluetooth), nonstandard RF remote, ISM band applications.

R. Fotedar, P. Garia, R. Saini, A. Vidyarthi, and R. Gowri [3] design and analyze comparative performance of microstrip patch antennas with different shapes of patch to find out the best shape. The resonant frequency is kept 2.4 $\mathrm{GHz}$ because of the great importance of this frequency in wireless communication. FR-4 dielectric substrate is used for all the designs as FR-4 dielectric substrate is a commonly used substrate in practice. Frequency and dielectric are same in all the cases so that performance analysis depends almost only on shape of the patch. Rectangular shape found good directivity and gain with respect to triangular and circular shape.

A. K. Maurya, A. Singh, P. Bipul, S. Srivastava, and R. Singh [7] presents a novel design of a Swastika shape microstrip antenna with compact nature and the study of various antenna parameters. The antenna is fed by coaxial probe feeding technique. Microstrip antenna is designed and simulated in CST simulation software. They design antenna at $1.7 \mathrm{GHz}$ (L-band) frequency, study and investigate the results using CST software. Authors use the same dielectric substrate 4.2, loss tangent.02 and same substrate height $1.6 \mathrm{~mm}$. The antenna size is very compact $(52.29 \mathrm{~mm} \times$ $67.74 \mathrm{~mm} \times 1.6 \mathrm{~mm}$ ) and covers $1.7 \mathrm{GHz}$ to $2.6 \mathrm{GHz}$. The designed antenna on $1.7 \mathrm{GHz}$ (L-band) frequency showing the bandwidth $21.7 \%$ and having return loss $-21.783 \mathrm{~dB}$. All the other respective results, i.e., VSWR, gain, directivity and power pattern of both the bands are shown with the help of CST software.

M. S. Hossain, M. M. Rana, M. S. Anower, and M. K. Islam [5] gives the information of performance analysis of $\mathrm{Z}$ shaped microstrip patch antenna designed using different dielectric substrate materials, substrate thickness and arm gap of patch, to operate in the frequency range of $0.6 \mathrm{GHz}$ to $2 \mathrm{GHz}$, By comparing different substrate material and thickness, FR4 material substrate is found to give much better performance than other. That designed antenna can be used for mobile broadband wireless protocols based on accepted specific use such as IEEE 802.20 or ATIS/ANSI HC-SDMA which can be operated at around 1.6 GHz. In some special case mobile phone networks, like GSM, use low microwave frequencies around $1.78 \mathrm{GHz}$. DVD-SH and $\mathrm{S}-\mathrm{DMB}$ use 1.452 to $1.492 \mathrm{GHz}$ frequencies. Global positioning satellite use $1.575 \mathrm{GHz}$ and $1.227 \mathrm{GHz}$.

\section{Design Of Microstrip PATCH ANTENNA}

To design a microstrip patch antenna, first substrate should be select, length of the patch should be calculate and finally feed position is decided so as to match the input impedance of the antenna with the characteristic impedance of feed line. The most commonly used feeding techniques are probe feed and microstrip line feed. Appropriate selection of dielectric material and its thickness is an important task for designing a microstrip patch antenna [8].

Microstrip antenna can be feed using different method such as Microstrip line feed, Inset feed, Co-axial feed etc. This paper considers Inset feeding. Copper $(\mathrm{Cu})$ is used for the patch, ground plane and microstrip feeding line of each antenna.

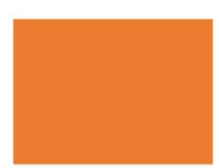

(a)

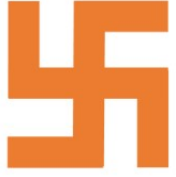

(b)
Fig. 1 (a) Rectangular (b) Swastika shape of patch of Microstrip Antenna

Three basic parameters for the Microstrip Patch Antenna design are:

a) Operating frequency $\left(\mathrm{f}_{\mathrm{o}}\right)$ : The ISM frequency band is $2400 \mathrm{MHz}$ to $2483.5 \mathrm{MHz}$, which is used for Bluetooth, WLAN and other applications. Hence the resonant frequency selected for design is $2.4 \mathrm{GHz}$.

b)Dielectric constant of the substrate $\left(\varepsilon_{\mathrm{r}}\right)$ : The dielectric material selected for design is FR4_epoxy having dielectric constant of 4.4. A substrate having high dielectric constant should be selected because higher the dielectric constant smaller the dimensions of the antenna.

c) Height of dielectric substrate (h): For the microstrip patch antenna which are used in cellular phones or other hand held devices it is essential that the antenna is not bulky. Hence, the height of the dielectric substrate should be small. Here FR4_epoxy substrate of standard height $1.6 \mathrm{~mm}$ is selected.

TABLE 1

Dimension used to design MPA

\begin{tabular}{lll}
\hline \multicolumn{1}{c}{ Parameters } & \multicolumn{2}{c}{ Dimensions } \\
& \multicolumn{1}{c}{ Rectangular } & \multicolumn{1}{c}{ Swastika } \\
\hline Patch width $(\mathrm{W})$ & $38.03 \mathrm{~mm}$ & $40 \mathrm{~mm}$ \\
Effective dielectric constant $\left(\varepsilon_{\text {reff }}\right)$ & 4.3996 & 3.0063 \\
Patch length extension $(\Delta \mathrm{L})$ & $0.748 \mathrm{~mm}$ & $0.7766 \mathrm{~mm}$ \\
Effective patch length (Leff) & $28.569 \mathrm{~mm}$ & $36.046 \mathrm{~mm}$ \\
Patch length (L) & $28.30 \mathrm{~mm}$ & $40 \mathrm{~mm}$ \\
Ground Plane Width $(\mathrm{Wg})$ & $37.9 \mathrm{~mm}$ & $60 \mathrm{~mm}$ \\
Substrate Width (Ws) & $37.9 \mathrm{~mm}$ & $60 \mathrm{~mm}$ \\
Ground Plane Length $(\mathrm{Lg})$ & $47.63 \mathrm{~mm}$ & $60 \mathrm{~mm}$ \\
Substrate Length $(\mathrm{Ls})$ & $47.63 \mathrm{~mm}$ & $60 \mathrm{~mm}$ \\
Inset feed depth $\left(\mathrm{y}_{\mathrm{o}}\right)$ & $8.1016 \mathrm{~mm}$ & $12 \mathrm{~mm}$ \\
\hline \hline
\end{tabular}

Design parameters of the Rectangular Microstrip patch antennas is calculated and tabulated in Table 1 for the known values of $\mathrm{f}_{\mathrm{r}}$ and $\varepsilon_{\mathrm{r}}$ using the design formulae [6]. 


\section{Simulation Results}

\section{a) S-parameter:}

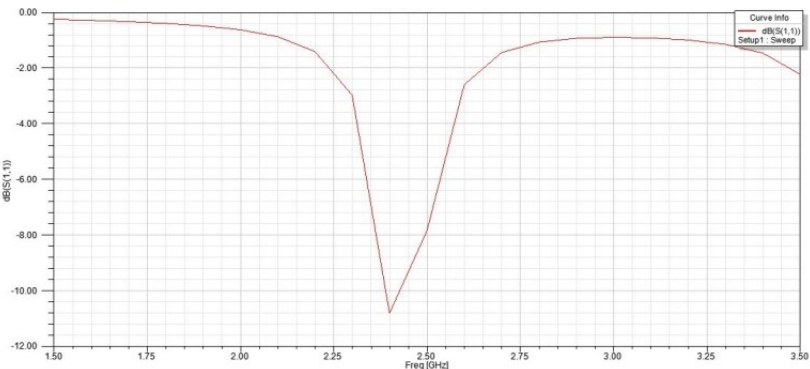

(a)

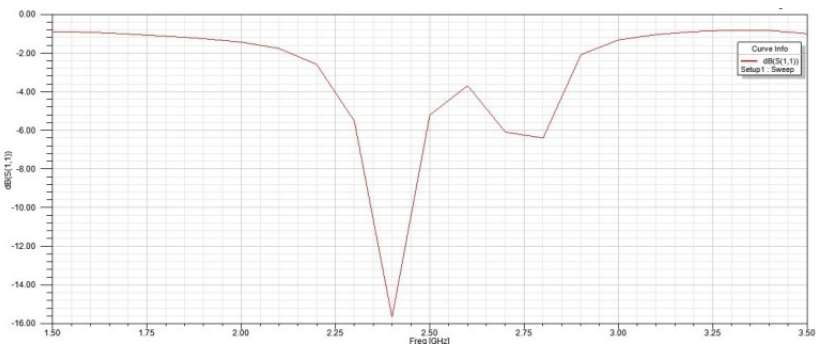

(b)

Fig. 2. S parameter of (a) Rectangular (b) Swastika Shaped Microstrip Patch Antenna (MPA)

b) VSWR:

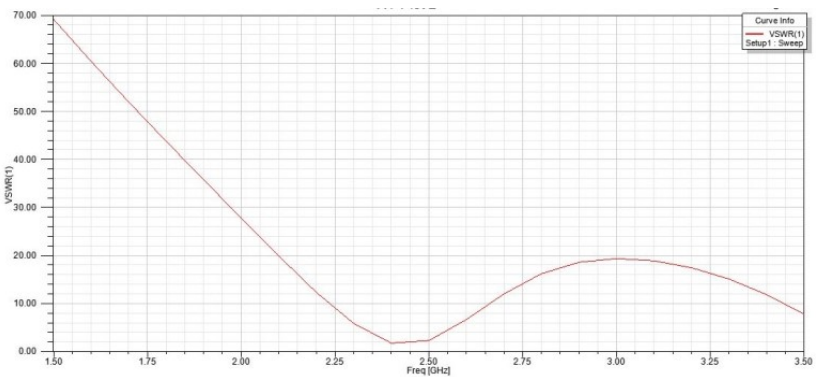

(a)

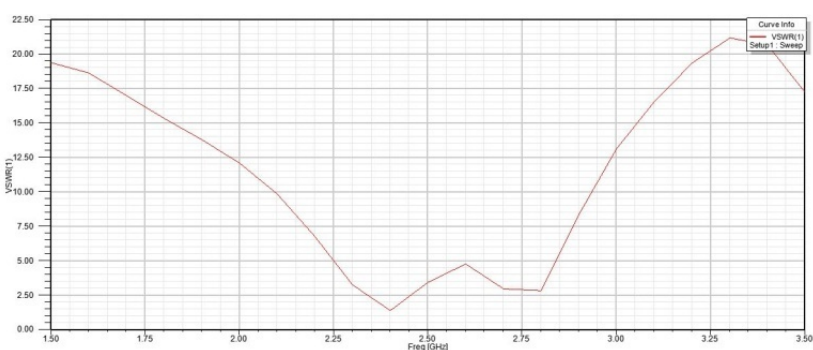

(b)

Fig. 3. VSWR of (a) Rectangular (b) Swastika Shaped MPA

c) Analysis: Return loss is the loss of power in the signal returned or reflected by a discontinuity in a transmission line or optical fiber. It is measured in $\mathrm{dB}$. Voltage standing wave ratio (VSWR) is defined as the ratio of partial standing wave's amplitude at an antinode of the amplitude at a node along the line. VSWR is $<2$. Antenna Bandwidth is the range of frequency over which an antenna maintains its certain characteristics, gain, polarization, VSWR, impedance etc. Radiation pattern is the graphical representation of field pattern of radiation from the antenna as a function of space coordinates.

The value of return loss, bandwidth and VSWR obtained from simulation are compared in Table 2

TABLE 2

Comparison of Return Loss, Bandwidth and VSWR of Rectangular and Swastika Shaped MPA

\begin{tabular}{cccc}
\hline \hline $\begin{array}{c}\text { Antenna Type } \\
\text { Parameter }\end{array}$ & $\begin{array}{c}\text { Return } \\
\text { Loss (dB) }\end{array}$ & $\begin{array}{c}\text { Bandwidth } \\
\text { (MHz) }\end{array}$ & VSWR \\
\hline Rectangular MPA & -10.7982 & 37.8 & 1.8108 \\
Swastika shaped MPA & -15.6513 & 109.9 & 1.3952 \\
\hline \hline
\end{tabular}

d) Radiation Pattern

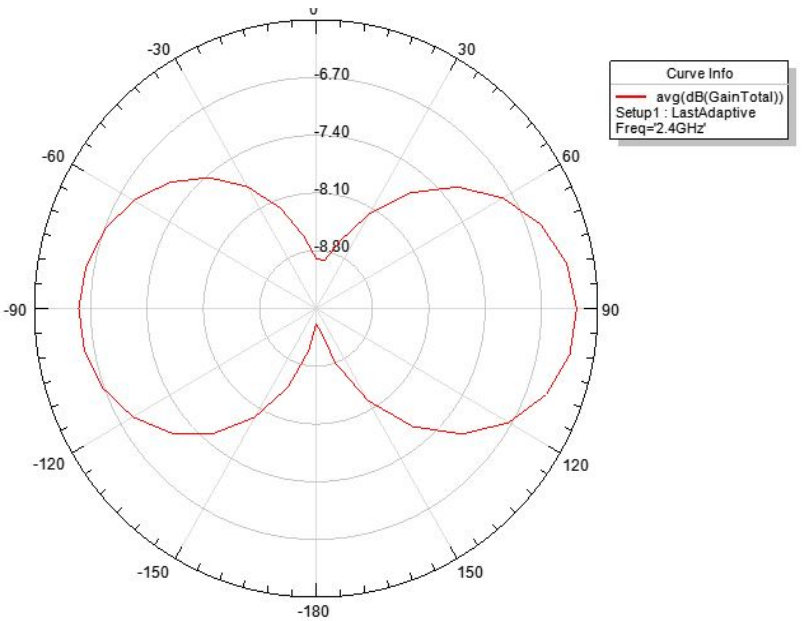

(a)

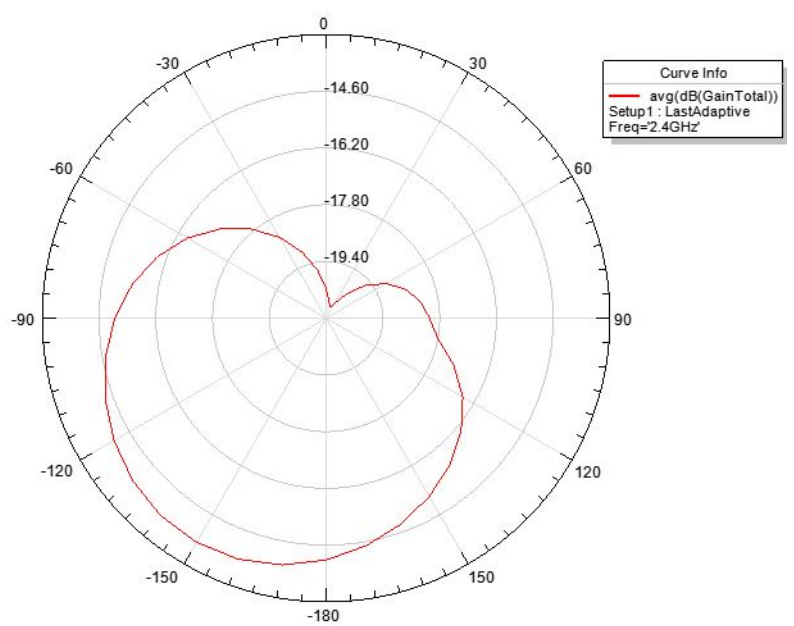

(b)

Fig. 4. Radiation Pattern of (a) Rectangular (b) Swastika Shaped MPA

\section{CONCLUSION}

The microstrip patch antenna with different shape of patch (rectangular and swastika shape) are designed in HFSS software and simulated for results. According to analysis 
done in previous section, the values of Return Loss, VSWR and bandwidth are $-15.6513 \mathrm{~dB}, 1.3952$ and $109.9 \mathrm{MHz}$ respectively for Swastika shaped MPA as compare to $10.7982 \mathrm{~dB}, 1.8108$ and $37.8 \mathrm{MHz}$ respectively for rectangular shaped MPA. The radiation pattern of rectangular shaped MPA is omnidirectional whereas radiation pattern for Swastika shaped MPA is directional. Although directional antennas help to focus the energy in particular direction which can help to overcome fading and multipath itself reduces the focusing power of directional antennas. So power efficiency in swastika shaped MPA is better than rectangular. So it is concluded that swastika shaped MPA performs better in comparison with better return loss, wide bandwidth, less VSWR and improved radiation Pattern and is more suitable for indoor use such as Bluetooth, WIFI etc.

\section{REFERENCES}

[1] S. Sharma, B. Bhushan, S. Gupta, and P. Kaur, "Performance Comparison of Micro-strip Antennas with Different Shape of the Patch," International Journal of u-and e-Service, vol. 6, 2013.

[2] M. H. Prio, M. M. U. Rashid, L. C. Paul, and A. K. Sarkar, "Total efficiency comparison of different shaped microstrip patch antennas having Defected Ground Structure," in 2015 International Conference on Electrical \& Electronic Engineering (ICEEE), 2015, pp. 265-268.

[3] R. Kant, P. Singh, and D. Dhubkarya, "Performance of Hshaped microstrip antenna using IE3D," in 2009 International Conference on Emerging Trends in Electronic and Photonic Devices\&Systems, 2009.

[4] R. Fotedar, P. Garia, R. Saini, A. Vidyarthi, and R. Gowri, "Performance Analysis of Microstrip Antennas Using Different Shapes of Patch at $2.4 \mathrm{GHz}$," in Advances in Computing and Communication Engineering (ICACCE), 2015 Second International Conference on, 2015, pp. 374-377.

[5] V. S. Rathor and J. P. Saini, "A Design of Swastika Shaped Wideband Microstrip Patch Antenna for GSM/WLAN Application," Journal of Electromagnetic Analysis and Applications, vol. 6, p. 31, 2014.

[6] M. S. Hossain, M. M. Rana, M. S. Anower, and M. K. Islam, "Investigation and performance analysis of $Z$ shaped migrostrip patch antenna for wideband application," in 2015 IEEE International Conference on Telecommunications and Photonics (ICTP), 2015, pp. 1-4.
[7] A. K. Maurya, A. Singh, P. Bipul, S. Srivastava, and R. Singh, "Design and analysis of swastik slot loaded microstrip antenna at fr4 lossy substrate on 1-band."

[8] L. C. Paul, M. S. Hosain, S. Sarker, M. H. Prio, M. Morshed, and A. K. Sarkar, "The Effect of Changing Substrate Material and Thickness on the Performance of Inset Feed Microstrip Patch Antenna," American Journal of Networks and Communications, vol. 4, pp. 54-58, 2015.

\section{BIOGRAPHIES}

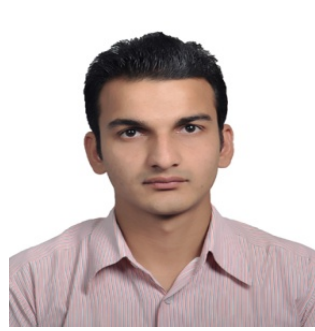

Suroj Burlakoti is an Electronics and Communication engineer. He is studying his M.Sc. degree in Information \& Communication Engineering and his Bachelor's of Engineering degree in Electronics and Communication Engineering from Tribhuvan University, Nepal. Currently, he is working as an Assistant lecturer in the Department of Electronics \& Computer Engineering at National College of Engineering. He is also Chief Technical director at Smart Nepali Pvt. Ltd. His areas of interests in research are Information and Communication, Embedded system, Electronics Devices \& Circuits, Microprocessor, Wireless \& Mobile Communication and Antennas.

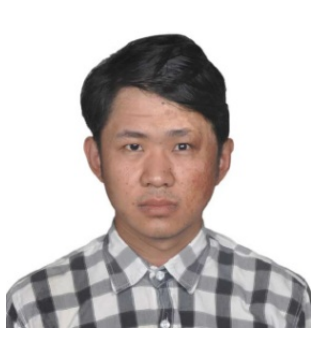

Prakash Rai is currently working as a Chief Developer of "Landslide Early warning System" at Smart Nepali Pvt. Ltd. He is also Lab instructor of Engineering Electromagnetics and Electronic device and Circuits at National College of Engineering, Lalitpur, Nepal. His areas of interest are Embedded System, Hardware Software Co-design, Signal Processing, Digital Communication Wireless \& Mobile Communication and Antennas. 